\title{
You can never step twice in the same river
}

\author{
Ruggero De Paulis, MD, and Luca P. Weltert, MD
}

\author{
From the Department of Cardiac Surgery, European Hospital, Rome, Italy. \\ Disclosures: Authors have nothing to disclose with regard to commercial support. \\ Received for publication June 6, 2018; revisions received June 6, 2018; accepted for publication June 7, 2018; \\ available ahead of print July 20, 2018. \\ Address for reprints: Ruggero De Paulis, MD, Department of Cardiac Surgery, European Hospital, Via Portuense \\ 700, Rome 00149, Italy (E-mail: Rdepaulis58@gmail.com). \\ J Thorac Cardiovasc Surg 2018;156:2121-2 \\ $0022-5223 / \$ 36.00$ \\ Copyright (c) 2018 by The American Association for Thoracic Surgery \\ https://doi.org/10.1016/j.jtcvs.2018.06.024
}

\begin{abstract}
"You can never step twice in the same river," so Heraclitus of Ephesus (535-475 BCE) explained the concept of the panta rhei (everything flows), which beautifully represents the first clear definition of space-time relativity. It took the genius of Albert Einstein to integrate this concept fully into the restricted relativity theory paradigm, finally making easy to understand for everyone that although we live in a 3-dimensional world, we live in it 4-dimensionally.
\end{abstract}

Although for most diseases the dimension of time is irrelevant, cardiovascular medicine has some peculiarities that make space-time thinking relevant. The average heartbeat accomplishes a full cycle in less than a second, moving all structures by a few centimeters and in the process displacing a significant volume of blood from the heart chambers to the great vessels. The novel technique of 4dimensional magnetic resonance imaging represents in fact the possibility of coupling spatial acquisition with time resolution. It encodes the velocity of flowing blood at each voxel in the volume, enabling fluid dynamics to be visualized by means of dedicated software. Because of the complexity of postprocessing and relatively long acquisition times, this technique is not yet routine in clinical use, but it holds potential as a groundbreaking technique to understand further the consequences of reconstructive or replacement heart valve and aortic surgical therapies. We have also recently used this fascinating technology to visualize optimal flow inside the sinuses of Valsalva, ${ }^{1}$ something Leonardo da Vinci magically and beautifully sketched in his Corpus of Anatomical Studies in the Windsor collection of Queen Elizabeth II.

The article by Bollache and colleagues ${ }^{2}$ in this issue of the Journal interestingly confirms the power of 4-dimensional magnetic resonance imaging to evaluate regional structural characteristics. This elegant study shows that for patients with bicuspid aortic valves, increased aortic valve-mediated wall shear stress is significantly associated with elastic fiber thinning, particularly with aortic valve stenosis and in the earlier stages of aortopathy. In turn, elastic fiber thinning correlates with impaired tissue biomechanics. consequences.

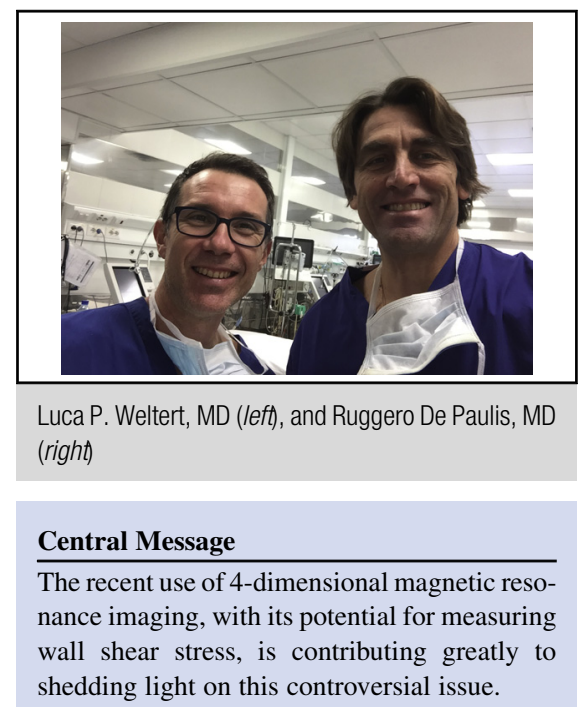

See Article page 2112.

These findings, clearly confirmed by histopathologic study of aortic tissue samples resected at surgery, further implicate valve-mediated hemodynamics in the progression of bicuspid aortic valve aortopathy. The information provided by this study starts to unravel the controversies and discussions about the origin of aortopathy in the context of a bicuspid valve or in relation to various morphologic types of bicuspid valve. The long-standing argument as to whether the aortopathy is genetically predetermined or rather depends on the eccentric flow hammering the aortic wall and initiating a degenerative process is beginning to be clarified. On the basis of the current data of Bollache and colleagues, ${ }^{2}$ we have finally arguments to assert that a bicuspid stenotic valve with time might induce progressive wall degeneration at the site where the jet impacts the aortic wall. The first direct consequence of this notion is the possibility that earlier aortic valve replacement might stop the process and, to some extent, prevent aortic dilatation. At the moment, other forms of aortopathy, such as the "root phenotype," similar to patients with Marfan syndrome and often associated with bicuspid valve insufficiency, appear to be genetically mediated, but the scientific evidence is still lacking, and a similar epigenetic mechanism may well be involved. For the time being, however, in both cases, waiting too long before surgery seems to increase the chance of aortic dilatation and its related 


\section{References}

1. Galea N, Piatti F, Sturla F, Weinsaft JW, Lau C, Chirichilli I, et al; Cornell International Consortium for Aortic Surgery (CICAS). Novel insights by 4D flow imaging on aortic flow physiology after valve-sparing root replacement with or without neosinuses. Interact Cardiovasc Thorac Surg. 2018;26:957-64.
2. Bollache E, Guzzardi DG, Sattari S, Olsen KE, Di Martino ES, Malaisrie SC, et al. Aortic valve-mediated wall shear stress is heterogeneous and predicts regional aortic elastic fiber thinning in bicuspid aortic valve-associated aortopathy. J Thorac Cardiovasc Surg. 2018;156: 2112-20.e2. 